\title{
Indigenous Treatment Methods of Small Ruminant Livestock in the Tropics -A Case Study from Katsina State, Nigeria
}

\author{
Rabiu Abdullahi ${ }^{1,2^{*}}$, Muhammad Awwal ${ }^{2}$ and Mamma Sawaneh ${ }^{3,4}$ \\ ${ }^{1}$ Department of Animal Sciences, Faculty of Agriculture, Universiti Putra Malaysia, 43400 Serdang, Malaysia \\ ${ }^{2}$ Departments of Agric Education, F.C.E. Katsina, Nigeria \\ ${ }^{3}$ Departments of Agribusiness and Information Systems, Faculty of Agriculture, Universiti Putra Malaysia, \\ 43400 Serdang Malaysia \\ ${ }^{4}$ School of Agriculture and Environmental Sciences, University of the Gambia, Brikama Campus, The Gambia
}

\begin{abstract}
This study was carried out in Jibia Local Government Area of Katsina State to establish the indigenous methods for treating small ruminant animals. Simple random approach was employed through questionnaire and interviews to collect information from 60 livestock farmers. The results indicated that the use of local methods of managing and preventing ruminant diseases are indeed effective and reliable. However, it may not be as effective as the scientific method. The farmers generally preferred and had more confidence in their local methods because the materials needed are readily accessible, affordable and easy to employ. Thus, in order to promote use of veterinary services in treating livestock, farmers should be able to afford and access such treatment services like locally treated methods.
\end{abstract}

Keywords: indigenous, Nigeria, small ruminants, treatment

\section{Introduction}

Indigenous small ruminants constitute greater percentage of ruminant population in Africa (Lebbie et al., 1994). These flocks of animals are commonly found in the rural areas where they are owned and managed under extensive system (Otchere, 1986). Small ruminants play an important role in the lives of most people especially rural farmers who livelihood entirely depend on them. They provide source of animal protein through their meat and milk (Fajemisin, 1991). Notwithstanding, they fetch a source of income when sold to meet some other family needs as well as play a vital social roles during ceremonies and festivals. Ruminants are group of animals that have four stomach compartments and entirely feed on plant based food for their daily intake. They comprise of buffalo, camel, cattle, sheep, goat, deer, etc. However, sheep and goat formed the largest number of small ruminant found in the tropics especially in Africa. In Nigeria, sheep and goat population is about 53 million. (FAOSTAT, 2009).

Small ruminant management is seriously hindered by diseases in the tropics. Diseases are very important to farmers and affect the production of small ruminants in several ways. It increases cost of production, lowers production level, reduces the quality and quantity of animal products and generally causes great loss to the farmer. Though, proven scientific methods of preventing and managing animal diseases in form of veterinary service abound, this may not always be readily available to rural farmers who are poor and less educated. Rural farmers are not well educated on the modern veterinary practices and drugs; and veterinary services are unavailable or unaffordable to them. However, the rural farmers have their own local methods of preventing and managing animal diseases. Such knowledge and practices are not well documented but are passed down orally from generation to generation. This study therefore seeks to make an attempt to identify some common diseases of small ruminant in the rural locality and the traditional methods used by farmers in preventing and managing small ruminant animal diseases. In doing this, the socioeconomic characteristics of the rural farmers, identified diseases, flock size, types and frequency of disease occurrence and the indigenous methods of preventing and managing small ruminant diseases are determined.

\section{Materials And Methods}

Study area

The study was conducted in Jibia Local Government Area of Katsina State. The town is located on coordinates of $13^{\circ} 05^{\prime} 30^{\prime} \mathrm{N}, 7^{\circ} 13^{\prime} 35^{\prime}$ ' $\mathrm{E}$ or $13.09167^{\circ} \mathrm{N}, 7.22639^{\circ} \mathrm{E}$. It is located in North-Eastern part of Katsina State with Sudan savannah vegetation and rainfall of about $600-700 \mathrm{~mm}$ per year. Farming is practiced in the area due to the presence of functional irrigation dam where animals are also reared. The town has a total area of $44 \mathrm{~km}^{2}$, population of 169,749 and shares border with neighboring town of Maradi in Niger Republic. 


\section{Data collection and analysis}

Data was obtained through personnel interviews with the aid of structure questionnaires. Sixty (60) ruminant farmers were randomly selected from the study area for this study. The farmers were engaged into discussion during data collection to clarify certain issues. Simple descriptive tools such as frequencies and percentages were used to analyses the data.

\section{Socioeconomic Profiles}

\section{Results And Discussion}

Most of the respondents (58.5\%) were married while $41.5 \%$ were single (Table 1). Obviously, the married farmers have more responsibilities to provide for their families hence are more likely to be engaged in small ruminant farming as a complimentary activity to meet up with their economic needs. The study however shows that the singles are not left out in small ruminant production as they constitute $41.5 \%$ respondents. They too have some needs to meet up with which could be for saving towards important life projects like education, housing, marriage and other purposes.

With respect to farmers' education, the results revealed that majority of the farmers $(48.5 \%)$ have only Qur'anic (Islamic) education. A considerable number (35\%) however have secondary education and only $7 \%$ have post secondary education. Education is very important and can likely influence the way farmers treat and handle their animals. It is believed that the respondents who had formal type of education may have been exposed to some theories and practices of animal health to some extent in the subject of agricultural science which forms part of the primary and secondary school curriculum (Adeneye et al., 2013). The result also shows that a considerable number of the respondents (41.5\%) practiced integrated farming system where they produced both crops and animals. Though, more respondents (58.5\%) reared only animals. This shows how important animal production is in the study area. None of the respondents reported producing crops only.

In this study, most of the respondents, up to $56.5 \%$ reported having flock size between the ranges of 21-100. About 29\% reported having between flock size of 1-10. The high number of flock size reported in this study can be attributed to the location of the study area. Generally, there are more small ruminants in northern part of Nigeria than elsewhere. Jibia happens to be located in the northern most part of the country. The town has Sudan savannah vegetation and much abundant land for grazing. There is an international livestock market at Jibia and a high flow of small ruminants from Niger republic into Nigeria through Jibia town. This could well be a reason for the large flock size reported in this study.

Table1: Socioeconomic characteristics of respondents

\begin{tabular}{lll}
\hline Characteristic & Frequency & Percentage \\
\hline Marital Status & 25 & 58.5 \\
Single & 35 & 41.5 \\
Married & & \\
\hline Educational Level & 29 & 48.5 \\
\hline Qur'anic education & 5 & 8.5 \\
Primary education & 21 & 35 \\
Secondary education & 5 & 8 \\
Post-Secondary education & & \\
\hline Farming System & 0 & 0 \\
\hline Crop production & 35 & 58.5 \\
Animal production & 25 & 41.5 \\
Crop and animal production & & \\
\hline Flock Size & 17 & 28.5 \\
\hline $1-10$ & 9 & 15 \\
$11-20$ & 24 & 56.5 \\
$21-100$ & & \\
\hline
\end{tabular}

Source: Field survey, 2011

\section{Disease Occurrence and Treatment of Diseases}

As discernible in table 2 , about $75 \%$ of the farmers reported that their animals did "not frequently" fall sick, only 10\% reported "very frequent" disease occurrence while $15 \%$ reported "frequently". This is an indication that there is no much prevalence and outbreak of small ruminant diseases in the study area. This could be attributed to the dry and harsh weather condition of the area which is unfavorable for disease causing microorganisms. The most common disease reported is mastitis which is about $37 \%$. Foot and mouth disease was also common with about $35 \%$ while Diarrhea and bloat having fewer occurrences each constituted $15 \%$. Among the small ruminants, Sheep were reported to be most affected by disease with $38.5 \%$ of farmers reporting them. Cattle were least affected as only $1.5 \%$ farmers stated.

The results further shows that most of the farmers about $94 \%$ reported diagnosing and treating their animals by themselves. When asked about what method they employed in treating their diseased animals, about 
$70 \%$ reported using local traditional methods of treatment. This corroborates the findings of Jegede et al., (2007), who reported in his studies that most farmers treated their animals by themselves and used traditional methods in the rural communities. This is possible because most farmers have experience of raising animals for years. They are able to identify, diagnose and treat animals using the local methods available to them. Observation was the predominant method of identifying diseased animals as $51.5 \%$ reported while $48.5 \%$ stated physical appearance (Table 2)

Farmers in this study mostly (48.5\%) reacted by treating their animals when the animal fell sick, $15 \%$ reacted by taking local preventive measures against further occurrence of disease while $13.5 \%$ reported sanitation. However, most farmers $(81.5 \%)$ were of the opinion that their local methods were more effective in treating diseased animals. Sangat-Roemantyo and Riswan (1990) also reported the effectiveness of using local herbs in treating various animal diseases. Herbs are readily available and accessible to the farmers and are effective while scientific methods have not been easily accessible to them. It is expected that the farmers perceive the superiority of their local methods over the scientific methods. Most of the respondents ( $45 \%$ ) based the effectiveness of their treatment methods on the fact that the animals are "beautifully recovered" while $20 \%$ based their fact on 'animal remain healthy'.

The table also shows that $21.5 \%$ of the respondents agreed that there are side effects while $78.5 \%$ observed no side effects from the animal as a result of using any of the local methods.

With respect to prevention measures, Table 2 further indicates that $20 \%$ of farmers prevent disease occurrence through regular vaccinations, while $36.5 \%$ indicated good management. However, $18.5 \%$ showed proper sanitation , $6.5 \%$ good feeding, $11.5 \%$ combined regular vaccination and sanitation, $1.5 \%$ each take sick animals to veterinary personnel and use recommended drugs respectively.

Farmers further expressed their opinions as seen in Table 2. It shows that $80 \%$ of the respondents believed that the local methods were more reliable and more economical than the scientific methods, while $5 \%$ still use scientific methods. However, 15\% employed both local and scientific methods. The inference taken from the above states that, the majority of the farmers believed in local method because it is cheaper and easy to employ, likewise it gives efficient results.

Table2: Disease Occurrence and Management of Small Ruminants by the Respondents

\begin{tabular}{|c|c|c|}
\hline Response & Frequency & Percentage \\
\hline \multicolumn{3}{|c|}{ Disease occurrence } \\
\hline Not frequently & 45 & 75 \\
\hline Frequently & 9 & 15 \\
\hline Very frequently & 6 & 10 \\
\hline \multicolumn{3}{|c|}{ Type of disease } \\
\hline Foot and mouth disease & 20 & 33.5 \\
\hline Mastitis & 22 & 36.5 \\
\hline Diarrhea & 9 & 15 \\
\hline Bloat & 9 & 15 \\
\hline \multicolumn{3}{|c|}{ Types of animals affected } \\
\hline Sheep & 23 & 38.5 \\
\hline Goat & 15 & 25 \\
\hline Sheep and goat & 21 & 35 \\
\hline Cattle & 1 & 1.5 \\
\hline \multicolumn{3}{|c|}{ Diagnosis and treatment } \\
\hline Self & 56 & 93.5 \\
\hline Veterinary personnel & 4 & 6.5 \\
\hline \multicolumn{3}{|c|}{ Method of identifying diseased animals } \\
\hline Observation & 31 & 51.5 \\
\hline Physical appearance & 29 & 48.5 \\
\hline \multicolumn{3}{|c|}{ Reaction to observed signs/symptoms } \\
\hline Treatment & 29 & 48.5 \\
\hline Prevention & 8 & 13.5 \\
\hline Proper sanitation & 8 & 13.5 \\
\hline Isolation & 2 & 3.5 \\
\hline Proper management & 4 & 6.5 \\
\hline Local prevention & 9 & 15 \\
\hline \multicolumn{3}{|c|}{ Perceived most effective method of treatment } \\
\hline Local & 48 & 80 \\
\hline Scientific & 3 & 5 \\
\hline Local and scientific & 9 & 15 \\
\hline \multicolumn{3}{|c|}{ Criteria for effectiveness of treatment method } \\
\hline Animal remain healthy & 12 & 20 \\
\hline Beautifully recovered & 26 & 45 \\
\hline Quick relief & 6 & 10 \\
\hline \multicolumn{3}{|c|}{ Side effect of method used } \\
\hline Yes & 13 & 21.5 \\
\hline
\end{tabular}


Indigenous Treatment Methods of Small Ruminant Livestock in The Tropics -A Case Study From

\begin{tabular}{|l|l|l|}
\hline No & 47 & 78.5 \\
\hline \multicolumn{2}{|c|}{ Disease prevention practices } \\
\hline Regular vaccination & 12 & 20 \\
Good management & 22 & 36.5 \\
Proper sanitation & 11 & 18.5 \\
Good feeding & 4 & 6.5 \\
Regular vaccination \& sanitation & 7 & 11.5 \\
Prevention & 1 & 1.5 \\
Taking to veterinary personnel & 1 & 1.5 \\
Using recommended drugs & 1 & 1.5 \\
\hline \multicolumn{2}{|c|}{ Recommended method of treating animals } \\
\hline Local & 48 & 80 \\
Scientific & 3 & 5 \\
Local and scientific & 9 & 15 \\
\hline
\end{tabular}

\section{Conclusion And Recommendation}

Most of the respondents in the study were married and the main type of education is Qur'anic education. The study found out that mixed farming is practiced in the area with most farmers having 20-100 ruminant animals. Disease occurrence was mostly not frequent with mastitis and foot and mouth disease being the most common diseases. Sheep were the most affected animals in terms of disease occurrence. Detection of disease was mainly based on observation and treatment was the major reaction when disease is detected. Most farmers treat their animals by themselves mostly using local methods because they think the local methods were effective and easy to employ. Farmers were able to determine the efficacy of their treatment methods when the animal recovered beautifully. Less case of side effects were discovered. Good management practices were mostly employed to prevent further occurrence of diseases. Farmers preferred and recommended the use of local methods of treating animals due to its effectiveness and ease of employment.

This study has revealed that local methods of managing and preventing ruminant diseases are indeed effective and reliable. However, cautionary measures should be taken as it may not be as effective as the scientific methods such as veterinary services. The farmers generally preferred and had more confidence in their local methods because the materials needed are readily accessible, affordable and easy to employ. Therefore, use of veterinary services in treating livestock, should be made affordable and accessible like locally treated methods.

\section{References}

[1]. Adeneye O.A., A. Wofala, O. and O. Sarah. (2013). Recent Curriculum Reforms in Primary and Secondary Schools in Nigeria in the New Millennium: Journal of Education and Practice, 4(5).

[2]. Anaeto, M., Tayo, G.O., Chioma, G.O and Afolabi, A.A. (2009). Comparative study of Albendazole and Papaya seed in ghe control of Gastrointestinal Nematodes in Goats. acta SATECH 3(1): 25 - 28

[3]. Chah, J., Igbokwe, E., and Chah, K. (2009). Ethnoveterinary medicine used in small ruminant health in the Eastern Guinea Sava nna, Nigeria. Livestock Research for Rural Development, 21 (12).

[4]. FAOSTAT (2009), http://faostat.fao.org/defaultaspx

[5]. Fajeminsin, B.A., (1991) "Goat milk production". In: National Animal Production and Research Institute Proceedings, Institute's Seminar, 1-13.

[6]. Harini Sangat-Roemantyo and Soedarsono Riswan (1991). Ethnobotanical aspects of medicinal plants for ruminants in Java in Traditional veterinary medicine for small ruminants in Java, Proceedings of a Workshop held at the Central Research Institute for Animal Science Bogor, Indonesia, 22 May, 1990, Indonesian Small Ruminant Network Bogor, Indonesia

[7]. Jegede, O., Bolorunduro, P., and Ikani, E. (2007). Levels of awareness and adoption of disseminated livestock technologies in Enugu state, Nigeria. Journal of Food Agriculture and Environment, 5(2), 185-189

[8]. Lebbie, S. H. B., Rey, B., and Irungu, E. K. (1994). Small Ruminant Research and Development in Africa: Proceedings of the Second Biennial Conference of the African Small Ruminant Research Network : AICC, Arusha, Tanzania, 7-11 December 1992: International Livestock Centre for Africa.

[9]. Otchere, E.O. (1986). Small ruminant production in tropical Africa. FAO Animal Production and Health Paper (FAO), no. 58 , 203210 